\title{
BMJ Open Does initial postgraduate career intention and social demographics predict perceived career behaviour? A national cross-sectional survey of UK postgraduate doctors
}

\author{
Gillian Marion Scanlan, ${ }^{\oplus 1}$ Jennifer Cleland, ${ }^{1,2}$ Suzanne Anderson Stirling, ${ }^{3}$ \\ Kim Walker, ${ }^{1,2,4}$ Peter Johnston ${ }^{1,4}$
}

To cite: Scanlan GM, Cleland J, Stirling SA, et al. Does initial postgraduate career intention and social demographics predict perceived career behaviour? A national cross-sectional survey of UK postgraduate doctors. BMJ Open 2019;9:e026444. doi:10.1136/ bmjopen-2018-026444

- Prepublication history and additional material for this paper are available online. To view please visit the journal (http:// dx.doi.org/10.1136/bmjopen2018-026444)

Received 1 September 2018

Revised 17 June 2019

Accepted 2 July 2019

Check for updates

(C) Author(s) (or their employer(s)) 2019. Re-use permitted under CC BY-NC. No commercial re-use. See rights and permissions. Published by BMJ.

${ }^{1}$ Centre for Healthcare Education Research and Innovation (CHERI), University of Aberdeen, Aberdeen, UK

${ }^{2}$ Institute of Education for Medical and Dental Sciences, University of Aberdeen, Aberdeen, UK

${ }^{3}$ Medical Directorate, NHS Education for Scotland (West Region), Glasgow, UK ${ }^{4}$ Medical Directorate, NHS Education for Scotland (North Region), Aberdeen, UK

Correspondence to Gillian Marion Scanlan; g.scanlan@dundee.ac.uk

\section{ABSTRACT}

Objective Studies indicate that initial career intentions and personal characteristics (eg, gender) can influence medical career decision-making. However, little is known about how personal characteristics and intention interact with career decision-making. To address this gap, we examined the link between career intention at the start of the 2-year UK Foundation Programme (FP) and career intentions on its completion.

Methods Data came from the 2017 UK National Career Destination Survey, a cross-sectional study completed by all second year foundation doctors. We included respondents' demographics (gender, graduate status on entry to medical school, career intention on starting the FP) and career intention as an outcome measure (eg, specialty (residency) training (UK), NHS non-training posts/further study, career break, working abroad). Multinomial regression was used to assess the independent relationship between background characteristics and career intention.

Results There were 6890 participants and 5570 usable responses. $55.9 \%$ of respondents were female and $43.1 \%$ were male, $77.1 \%$ were non-graduates and $22.9 \%$ were graduate entrants to medical school. Approximately twothirds $(62.3 \%, n=2170)$ of doctors who had an original intention to pursue specialty training after F2, still intended to do so on completion. Most of those who stated at the start of F2 that they did not want to pursue specialty indicated at the end of F2 they would be undertaking other employment opportunities outwith formal training. However, $37.7 \%$ of respondents who originally intended to pursue specialty training on FP completion did something different. Graduate entrants to medicine were more likely to immediately progress into specialty training compared with their peers who did medicine as a primary first degree.

Conclusion Original intention is a strong predictor of career intentions at the end of the FP. However, a considerable proportion of doctors changed their mind during the FP. Further research is needed to understand this behaviour.

\section{INTRODUCTION}

Over a number of years now, the number of UK Foundation Programme (FP) doctors
Strengths and limitations of this study

- This is the first study to examine the link between career intention on starting the 2-year UK Foundation Programme (FP) and career intention on its completion.

- This was a national survey of all 2016-2017 FP2 doctors, with $73.6 \%$ usable responses.

We focus on the relationship between gender, graduate status and career intention, and application for a training (residency) post, service post or other option. We did not look at specific specialty intention.

- Data were self-reported and not cross-referenced with training post applications and acceptances.

- The study design means we do not know why career intentions and behaviour remained consistent or changed.

pursuing higher training has declined. ${ }^{1-3}$ In 2017 , the figures showed that only $42.6 \%$ of those completing the FP were pursuing specialty or core training posts at the end of the $\mathrm{FP},{ }^{4}$ which is the first possible time to apply for specialty (residency) training within the UK. Instead, most doctors at this stage of their career are opting to take a career break or work in non-training posts (clinical fellowships, locum posts, academic study or service provision roles). This has negative implications for service delivery in terms of unfilled training posts, and longer-term consequences in terms of insufficient doctors' training to consultant level.

The initial career choice of medical students has been shown to be a good predictor of eventual career behaviour. ${ }^{5-9}$ Medical students who have an original intention to work in certain specialities or locations throughout medical school are more likely to pursue these interests in their early 
postgraduate years or as qualified doctors many years later. $^{6} 910$ In addition, qualified physicians who show intentions to leave clinical practice have a greater likelihood of doing so than their counterparts without these intentions. ${ }^{1112}$

These findings, that intention is strongly related to future (career) behaviour, are in line with the theory of planned behaviour (TPB). ${ }^{13-15}$ According to the TPB an intention to undertake a behaviour is a consequence of person's attitude towards it, subjective norm (social pressure to perform a behaviour) and perceived behavioural control (the ease or difficulty of performing a behaviour). ${ }^{16-18}$ Thus, intentions are a prerequisite of behavioural intentions, and intention becomes an accurate predictor of a planned behaviour. ${ }^{14}{ }^{18}$ Studies have highlighted the association between TPB variables, self-efficacy and demographic factors in predicting career intentions of multiple occupational groups and diverse populations. ${ }^{16-21}$ However, within the context of medicine and career behaviour, the literature on career intention and social demographics is typically atheoretical, shows mixed results and usually focuses on medical students or qualified healthcare professionals, ${ }^{18}{ }^{22-34}$ and/or other recruitment and retention of early career doctors into rural or primary care posts. ${ }^{6} 10$

Many authors have focused on medical student career decision-making, particularly specialty choice. ${ }^{5} 22262732$ However, to the best of our knowledge, there has been no previous research looking at the association between initial postgraduate career intention and career intentions in doctors at the stage of applying for a specialty training post. Yet, this intelligence is critically important as it can inform policy in terms of how many more doctors are needed to be trained in order to have an adequate consultant workforce in the future, as well as informing the future research agenda on this topic.

To address this gap in the literature, our aim was to examine the relationship between early postgraduate career intentions and social demographic factors, and career behaviour (or next career step). Drawing on previous studies, we were particularly interested in the influence of gender and graduate status, ${ }^{29} 313536$. Our assumption was that those who entered medicine as graduates may be more likely to move through the postgraduate training pathway without taking time out compared with their peers who studied medicine as an undergraduate degree (as is still the norm in the UK). Although previous studies have identified gender differences in medical careers preferences, ${ }^{28} 3034$ more recent work with early career UK doctors has shown few differences between men and women ${ }^{37}$ so we anticipated limited differences between the career intentions of these groups. Finally, and as discussed above, our final focus was relationship between career intention and career choices given the wider literature and our own previous qualitative work. ${ }^{6} 103839$
METHODS

\section{Context}

Medical students spend between 4 and 6 years at university developing their clinical and professional skills to be doctors. The norm is a 5 -year programme where most students have progressed into medical school immediately on leaving secondary (high) school. About $10 \%$ of the UK medical programmes are 4 years in length, aimed at graduate entrants (but note there are also many graduates on standard 5-year programmes, and around 25\% of the UK medical student population are graduates). ${ }^{40}$ Six-year programmes are those which either include an intercalating year or a pre-entry year. After graduation, over $98 \%$ of medical students apply for the 2-year FP. This training programme is a structured, competency-based, and outcome-focussed programme over 2 years, managed by 22 'Foundation Schools' across the UK (Scotland, England, Wales and Northern Ireland). The foundation training curriculum is designed to ensure a broad base of training across all programmes including medical and surgical specialties, to prepare doctors for further postgraduate training (residency posts). In the UK, these posts, hereafter referred to collectively as specialty training, include core followed by higher specialty training in some disciplines (eg, medicine, anaesthesia) and run through training in others (eg, obstetrics and gynaecology, general practice). At the end of the first foundation (F1) year, trainees obtain full registration with the UK regulator (General Medical Council (GMC)). If they are expected to achieve all their FP competencies at the end of the second year, they are eligible to apply for specialty training in foundation year 2 (F2). The application process and associated post/job offers take place a few months before the end of the FP, so F2 doctors know their next career move in advance and can start making plans to, for example, move to a new city.

Each year, those in the second year of the FP (commonly referred to as F2 doctors) complete the mandatory Career Destination Survey. The destination survey was originally set up by a number of different foundation schools to assess where their trainees were going after the FP. When the survey was first envisioned there was no way of tracking trainees and no databases were linked together. Each school uses the same core questions in the questionnaire, but each can also add their own. This survey is sent out in the last few months of F2, after doctors have made decisions about the next step in their careers, such as applying for specialty training. It is a self-reported survey that is used to collect information on individual characteristics and post-foundation training career intentions/ plans. Questions include original career intentions at the start of F1; whether or not the respondent has applied for, and accepted, a specialty training post (residency); or is planning to take an NHS non-training post, a career break or an academic post (see earlier) at the end of F2; as well as sociodemographic questions. The survey data are traditionally used for quality management and workforce planning purposes, but we were given access to 
examine the data for research purposes. Please refer to online supplementary file one for an example of the core questions included.

\section{Sample and data collection}

The email containing the link about the Career Destinations Survey was sent out to F2 doctors by 21 UK foundation schools who are responsible for the management of the survey in May 2017 ( $\mathrm{n}=6890)$. One foundation school had a paper version that was provided to their F2 doctors to complete. This number includes 6314 doctors completing the Standard Foundation Programme and 445 completing the Academic Foundation Programme (131 did not declare their 'Type of Foundation Training' in the survey). The survey was opened between May 2017 and closed in September 2017 (note that F2 finished at the end of July/beginning of August, but the survey was kept open after that date to maximise response rate). Several reminder emails were sent out to encourage responses. Participants could review their survey before submission or could go back to previous questions.

No formal sample calculation was undertaken as we were surveying the entire population of F2 doctors working in the UK in 2016-2017.

\section{Data management}

The content of the Career Destination Survey differs slightly across the four UK nations (England, Scotland, Northern Ireland and Wales) but there is a minimum core dataset. The foundation schools varied in how they collected the data, but the majority used an online survey tool. One small school used a paper copy and the results were manually transferred to a spreadsheet. Survey responses were checked to ensure only one complete response was counted per invited participant. The resulting data for the surveys delivered online were downloaded into excel documents. These raw data were cleaned then transferred into SPSS for data analysis. Data checking and quality assurance was undertaken by two researchers (GS and SS) to ensure baseline figures were validated and no errors have been made on transferring files from excel to SPSS.

\section{Analysis}

All the data were analysed using SPSS (IBM SPSS Statistics for Windows V.22.0). The results are reported in terms of numbers, percentages and/or ORs as appropriate. Univariate analysis $\left(\chi^{2}\right)$ was used to investigate the relationship between three predictor variables against the dependent (outcome) variable. The predictor variables were: gender, graduate status and F1 Intention (ie, career intention on entering the FP). For ease of reporting and interpretation, the predictor variables were divided into binary variables:

1. Gender-male and female.

2. Graduate status-school leaver on entry to medical school or graduate on entry to medical school.
3. F1 intention-intention to apply for specialty training after F2, or no intention.

The reference categories for each predictor variable are as follows; for gender, 'male', for graduate status, 'graduate' and F1 intention, 'intention to progress into specialty training'. The dependent (outcome) variable was career behaviour and was made up of four categories referring to the next career step: specialty training (UK), UK employment/further study, career break and working abroad. UK employment/further study refers to clinical teaching fellowships, locum posts, further academic study (including diplomas, masters and $\mathrm{PhD}$ opportunities) and NHS junior doctors posts, which are currently outside recognised training structures. The reference category for the outcome variable (dependent) was 'specialty training (UK)'; each of the other three categories (UK employment/further study, career break and working abroad) was compared with this reference group.

Given our dependent variables were categorical and there were more than two categories, we then conducted a multinomial logistic regression analysis to test whether the independent variables could be used to predict the likelihood of trainees choosing a specific career behaviour in relation to specialty training (the reference category). The multinomial logistic regression analysis was employed to predict the odds of F2 doctors pursuing specialty training in the UK after the F2 programme, based on an F1 career intentions, gender and graduate status. Only variables that showed significant associations at the univariate level were entered into the regression model.

\section{Patient and public involvement}

Patients were not involved in any aspect of this study given the focus was career intentions and behaviour of a group of doctors in their early years of training.

\section{Ethics}

Those completing the Career Destinations Survey give permission for their data to be used for research purposes. One member of the team (SS) worked directly with the survey dataset. All identifying details (eg, GMC number) were removed before analysis, so no other member of the research team had access to identifiable data. Ethical permission was granted for this study from the University of Aberdeen College of Life Sciences and Medicine Ethics Research Board (CERB/2015/12/1269, approval granted 25/01/16).

\section{RESULTS}

The Career Destinations Survey was sent out to F2 doctors via email by all 22 UK Foundation Schools Programme directors in August $2017(\mathrm{n}=6890)$. Unfortunately, the approach to survey administration meant some respondents completed the survey more than once and some doctors received and completed the survey in error, giving 7563 responses. After cleaning (removing duplicates, 


\begin{tabular}{|c|c|c|}
\hline & Frequency & Percent \\
\hline Gender: female & 3853 & 55.9 \\
\hline Gender: male & 2977 & 43.2 \\
\hline Gender: total & 6830 & 99.1 \\
\hline Gender: missing & 60 & 0.09 \\
\hline Graduate entrant: yes & 1572 & 22.9 \\
\hline Graduate entrant: no & 5287 & 77.1 \\
\hline Graduate entrant: total & 6859 & 99.6 \\
\hline Graduate entrant: missing & 31 & 0.4 \\
\hline F1 intention: specialty training (UK) & 3713 & 53.9 \\
\hline $\begin{array}{l}\text { F1 intention: no intention to apply for } \\
\text { specialty training }\end{array}$ & 2106 & 30.6 \\
\hline F1 intention: no FY1 year & 23 & 0.33 \\
\hline $\begin{array}{l}\text { F1 intention: undecided about } \\
\text { career path }\end{array}$ & 1047 & 15.20 \\
\hline F1 intention: total & 6889 & 99.9 \\
\hline F1 intention: missing & 1 & 0.1 \\
\hline $\begin{array}{l}\text { Career behaviour: specialty training } \\
\text { (UK) }\end{array}$ & 2792 & 41.0 \\
\hline $\begin{array}{l}\text { Career behaviour: other employment } \\
\text { UK/further study }\end{array}$ & 2337 & 34.32 \\
\hline Career behaviour: working abroad & 404 & 5.9 \\
\hline $\begin{array}{l}\text { Career behaviour: other employment } \\
\text { (UK or abroad) }\end{array}$ & 1 & 0.01 \\
\hline $\begin{array}{l}\text { Career behaviour: specialty training } \\
\text { (UK or abroad) }\end{array}$ & 3 & 0.04 \\
\hline Career behaviour: deferred & 178 & 2.61 \\
\hline Career behaviour: turned down & 103 & 1.5 \\
\hline Career behaviour: career break & 951 & 13.9 \\
\hline Career behaviour: left medicine & 41 & 0.6 \\
\hline Career behaviour: total & 6810 & 98.83 \\
\hline Career behaviour: missing & 80 & 1.16 \\
\hline Total number of respondents & 6890 & 100 \\
\hline
\end{tabular}

and invalid responses), we had a total of 5570 usable responses. This gives a response rate of $80.1 \%$. Additionally, only complete cases where used in the analysis of the $\chi^{2}$ tests and the multinomial regression analysis.

Participant characteristics can be seen in table 1 . Of our respondents, $55.9 \%(n=3853)$ were female and $43.2 \%$ $(n=2977)$ were male. Sixty participants did not indicate their gender preference and thus were coded as missing data. The $\chi^{2}$ showed statistically significant associations between gender and career behaviour. Please see table 2 for the full results of the $\chi^{2}$ tests. Approximately half of male $(52.0 \%, \mathrm{n}=1452)$ and female F2 (49.7\%, n=1804) doctors opted for UK employment/further study or a career break after the F2 programme. A slightly lower proportion of male doctors $(41.7 \%, \mathrm{n}=1164)$ pursued specialty training compared with their female peers (44.2\%, n=1607). Approximately $6 \%$ of males $(6.4 \%$, $\mathrm{n}=178)$ and females $(6.1 \%, \mathrm{n}=223)$ went abroad to work after the $\mathrm{F} 2$ programme.

Over three-quarters-76.7\% ( $\mathrm{n}=5287)$ - were non-graduates on entry to medical school and $22.8 \% \quad(n=1572)$ were graduates reflecting UK norms. Thirty-one respondents did not indicate whether they were a graduate or not. $86.7 \%(n=5977)$ were under 29 years old and $13.1 \%$ $(n=904)$ were over the age of 29 years old. Nine individuals did not indicate their age. The $\chi^{2}$ test for graduate status and career behaviour was significant. The majority of those who entered medical school as graduates opted for a training post immediately after the FP $(52.7 \%$, $\mathrm{n}=780)$. This compares to $40.2 \%(\mathrm{n}=2000)$ of those who entered medicine without a first degree (typically directly from school, as is the norm in the UK). In keeping with this pattern, more non-graduates $(53.2 \%, \mathrm{n}=2643)$ were pursuing UK employment/further study or a career break after F2 than F2 doctors who were graduates on entry to medical school. More of those taking medicine as their primary degree (non-graduates) planned to work abroad after the FP $(6.7 \% \quad(n=332)$ than did their graduate-entry peers $(4.7 \%(\mathrm{n}=70))$.

Doctors were asked to indicate their next career destination (after completing F2 training). 40.5\% ( $\mathrm{n}=2792)$ were going directly into specialty training. $33.9 \%$ $(\mathrm{n}=2337)$ were going directly into a non-training position within the UK. $13.8 \%(\mathrm{n}=951)$ were undertaking a career break. However, only $5.9 \%(n=404)$ were going abroad to work. Eighty participants did not complete this question, 4 did not indicate where their next position would be located, 103 turned down specialty due to location, 178 had deferred training and 41 had left medicine, and thus were omitted in the final analysis. Please see figures 1 and 2 for a full breakdown of those excluded from the final analysis. The $\chi^{2}$ tests for intention at the start of the FP and intended career behaviour at the end of the FP were significant. Approximately two-thirds $(62.3 \%, \mathrm{n}=2170)$ of doctors who had an original intention to pursue specialty training after F2 did so on F2 completion. Similarly, most of those who stated at the start of F2 that they did not want to purse specialty training, did not do so, $52.8 \% \quad(n=1055)$ pursued other UK employment or further study, $21.2 \%$ $(\mathrm{n}=423)$ undertook a career break and $12.1 \% \quad(\mathrm{n}=242)$ went abroad. However, $\sim 40 \%(24.5 \%, \mathrm{n}=854)$ of those who had originally intended to pursue specialty training did not do so, instead opting for UK employment/further study $(24.5 \%, \mathrm{n}=854)$ (ie, clinical teaching fellowships, locum posts, further academic study, NHS non-training posts), a career break $(10.5 \%, \mathrm{n}=366)$ or went abroad to work $(2.7 \%, \mathrm{n}=93)$. Conversely, $13.9 \% \quad(\mathrm{n}=270)$ of those individuals who did not intend to pursue specialty training at the outset of the FP, did apply for a specialty/ core/GP training post.

\section{Multinomial regression model}

Results of the multinomial regression are presented in table 3 . The Pearson $\chi^{2}$ goodness-of-fit test indicated that the model was a good fit to the data, $\mathrm{p}=0.30$. However, 
Table $2 \chi^{2}$ results

\begin{tabular}{|c|c|c|c|c|c|}
\hline & Specialty training & $\begin{array}{l}\text { UK employment/ } \\
\text { further study }\end{array}$ & $\begin{array}{l}\text { Working } \\
\text { abroad }\end{array}$ & Career break & Total \\
\hline \multicolumn{6}{|l|}{ Predictor variables } \\
\hline $\begin{array}{l}\text { Graduate status: school leaver } \\
\text { on entry to medical school }\end{array}$ & $2000(40.2 \%)$ & $1903(38.3 \%)$ & $332(6.7 \%)$ & $740(14.9 \%)$ & 4975 \\
\hline $\begin{array}{l}\text { Graduate status: graduate on entry } \\
\text { to medical school }\end{array}$ & $780(52.7 \%)$ & $425(28.7 \%)$ & $70(4.7 \%)$ & $205(13.9 \%)$ & 1480 \\
\hline \multicolumn{6}{|c|}{ Graduate status $=\chi^{2}(3, n=6455)=77.88, p \leq 0.001$} \\
\hline Gender: male & $1164(41.7 \%)$ & $1090(39.0 \%)$ & 178 (6.4\%) & 362 (13.0\%) & 2794 \\
\hline Gender: female & $1607(44.2 \%)$ & $1227(33.8 \%)$ & $223(6.1 \%)$ & 577 (15.9\%) & 3634 \\
\hline \multicolumn{6}{|c|}{ Gender $=\chi^{2}(3, n=6428)=23.84, p \leq 0.001$} \\
\hline $\begin{array}{l}\text { F1 intention: intention to apply for } \\
\text { specialty training }\end{array}$ & $2170(62.3 \%)$ & $854(24.5 \%)$ & $93(2.7 \%)$ & $366(10.5 \%)$ & 3483 \\
\hline $\begin{array}{l}\text { F1 intention: no intention to apply for } \\
\text { specialty training }\end{array}$ & $278(13.9 \%)$ & $1055(52.8 \%)$ & $242(12.1 \%)$ & $423(21.2 \%)$ & 1998 \\
\hline \multicolumn{6}{|c|}{ F1 intention: $\chi^{2}(3, N=5481)=1242.72, p \leq 0.001$} \\
\hline
\end{tabular}

as highlighted in table 3 , the $\mathrm{p}$ value is not statistically significant. Graduate status on entry to medical school, gender and $\mathrm{F} 1$ intention all remained significant predictors of doctors pursuing specialty/core/GP training or not on completion of the FP. Non-graduates were more likely than those who entered medicine as graduates to pursue UK employment/further study than immediately

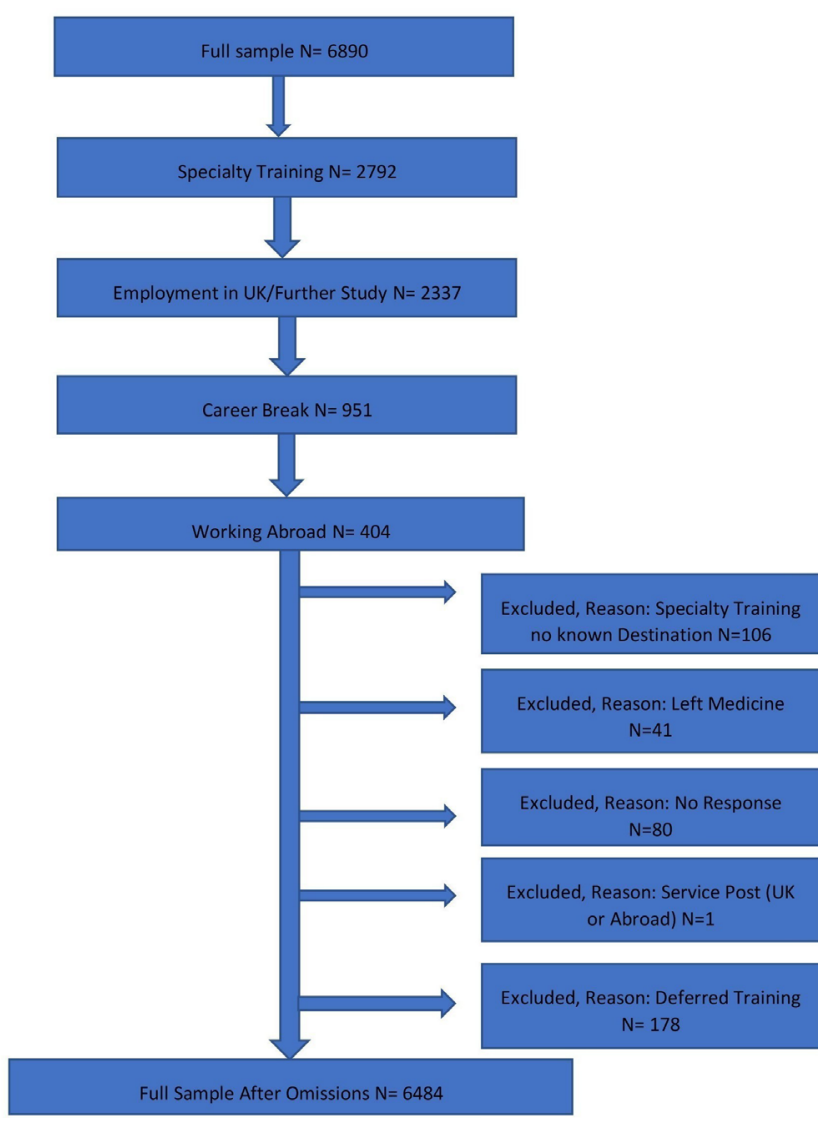

Figure 1 Career destination omissions. progress into a training (residency) post. The odds of non-graduates (those taking medicine as their primary degree) undertaking UK employment/further study after F2 were 1.50 times the odds of a graduate doctor doing so $(95 \%$ CI 1.30 to 2.00$)$. Similarly, non-graduates on entry to medical school were more likely to work abroad after the FP than go into specialty training. The odds of a non-graduates going abroad to work were 1.54 times the odds of a graduate entrant doctor doing so (95\% CI 1.12 to 2.10). The odds of male doctors undertaking other UK employment/further study after F1 were 1.27 times the odds of a female doctor doing so (95\% CI 1.10 to 1.43). Doctors who intended to apply for specialty training were less likely than those without this intention to immediately progress into other UK employment/further study, take a career break and work abroad. The odds of a doctor with an intention to immediately progress into specialty training going abroad $(\mathrm{OR}=0.06,95 \% \mathrm{CI} 0.04$

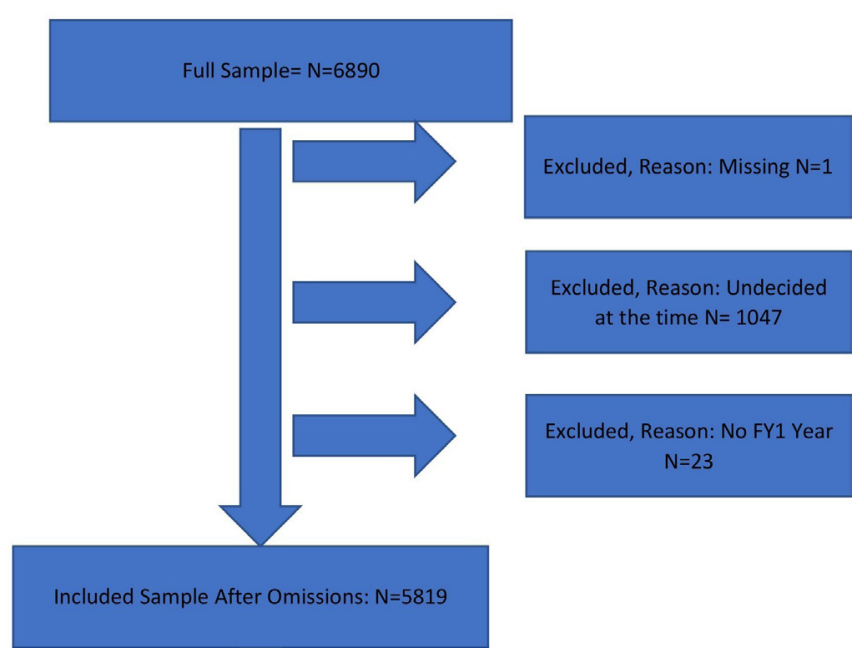

Figure 2 F1 intention omissions. 
Table 3 Results of the multinomial regression analysis

\begin{tabular}{|c|c|c|c|c|c|c|}
\hline \multirow[b]{2}{*}{$\begin{array}{l}\text { Predictor } \\
\text { variables }\end{array}$} & \multicolumn{2}{|c|}{ UK employment/further study } & \multicolumn{2}{|c|}{ Working abroad } & \multicolumn{2}{|l|}{ Career break } \\
\hline & B (SE) p-value & $\begin{array}{l}\text { OR }(95 \% \mathrm{Cl} \text { for } \\
\text { OR) }\end{array}$ & B (SE) p-value & $\begin{array}{l}\text { OR }(95 \% \text { CI for } \\
\text { OR) }\end{array}$ & B (SE) p-value & $\begin{array}{l}\text { OR }(95 \% \mathrm{Cl} \text { for } \\
\text { OR) }\end{array}$ \\
\hline Intercept & $1.00(0.10)^{\star \star}$ & & $-0.70(0.20)^{\star *}$ & & $0.21(0.11)$ & \\
\hline $\begin{array}{l}\text { Graduate status: } \\
\text { school leaver } \\
\text { on entry to } \\
\text { medical school }\end{array}$ & $0.40(0.10)^{\star \star}$ & 1.50 (1.30 to 2.00$)$ & $0.43(0.16)^{\star}$ & 1.54 (1.12 to 2.10$)$ & $0.12(0.10)$ & $1.13(0.92$ to 1.40$)$ \\
\hline Gender: male & $0.23(0.07)^{\star}$ & 1.27 (1.10 to 1.43$)$ & $0.07(0.12)$ & 1.07 (0.84 to 1.40$)$ & $-0.14(0.08)$ & 0.90 (0.76 to 1.10$)$ \\
\hline $\begin{array}{l}\text { F1 intention: } \\
\text { intention for } \\
\text { specialty training }\end{array}$ & $-2.13(0.08)^{\star \star}$ & $0.12(0.10$ to 0.14$)$ & $-3.00(0.14)^{\star \star}$ & 0.06 (0.04 to 0.07$)$ & $-2.10(0.10)^{\star \star}$ & $0.13(0.10$ to 0.15$)$ \\
\hline
\end{tabular}

Total number of participants: 5819 .

Goodness-of-fit $\chi^{2}=\chi^{2}(12)=14.01, p=0.30$.

${ }^{*} \mathrm{p}<0.01 ;{ }^{* \star} \mathrm{p}<0.001$. Reference outcome category: specialty training. Reference category for predictors: female, graduate status and no intention.

to 0.07 ), seek other UK employment/study opportunities $(\mathrm{OR}=0.12,95 \% \mathrm{CI} 0.10$ to 0.14$)$ or take a career break were $(\mathrm{OR}=0.13,95 \% \mathrm{CI} 0.10$ to 0.15$)$ were lower than the odds for those without these intentions.

\section{DISCUSSION}

To the best of our knowledge, this is one of the first studies that has directly examined the relationship between individual (sociodemographic) characteristics with doctors' career intentions at the very beginning of generic postgraduate training (the FP) and at the time when they are first eligible to apply for specialty training (in the second year of the FP, F2). This is an important step forward as the Career Destinations Survey data are influential in terms of workforce planning and policy and this paper provides more nuanced analysis than has been available previously.

We found that most respondents behaved in line with their original F1 intentions whether these intentions be to immediately progress into a specialty training post or pursue another option (such as an NHS post outside recognised training structures, or fellowship). Interestingly, those doctors who indicated their original intention was to pursue specialty training were more likely to pursue this behaviour than any other. However, $~ 38 \%$ of doctors who had the intention to go directly into a training post at the end of F2 did not do so. In contrast, only $14 \%$ of those without this original intention changed their mind and did go into a training post at the end of F2.

This highlights that a considerable proportion of doctors change their mind about their career during the FP, and for most of them this is in the direction of taking time out of training. The nature of the data does not allow us to identify what influences this switch but recent research with F2 doctors has confirmed that positive or negative relationships and or experiences throughout the FP is enough to influence whether doctors will go immediately into training or take some time out. ${ }^{39} 4142$ The UK-GMC National Training Survey ${ }^{43}$ Initial Findings report notes that nearly a quarter of trainees feel burnt out, a third feel exhausted and worn out and a half work over their rostered hours on a daily or weekly basis. This may provide circumstantial explanation of trainees' change in intention.

Those who entered medical school as graduates were more likely to take up a training post immediately post-FP compared with non-graduates. The nature of the data does not provide an explicit reason for this. However, it may be that those entering medical school as graduates, who tend to have more life experience, feel more confident or more prepared for specialty (residency) training than their younger peers. ${ }^{44}$ From a theoretical perspective, this would be in line with Banduras concept of self-efficacy which relates to an individual's confidence or belief in their own abilities to perform a given behaviour. ${ }^{45-47}$ This pattern in the survey responses merits further study, ideally using qualitative methods to explore the differences between the two groups in more depth.

Additionally, and possibly more likely, foundation doctors who were graduate entrants to medicine are likely to be older (ie, over 29 years old), have more financial debts ${ }^{2} 8$ and more likely to have a family or spouse for whom they are responsible, ${ }^{29}$ so delaying entry into training may be unattractive for practical reasons. However, older mature junior doctors have more problems in progressing through their specialty training ${ }^{29}$ and they are more likely to experience higher levels of psychological distress than their younger counterparts. ${ }^{49}$ Again, this deserves further exploration. However, in short, our data coupled with previous research does not suggest that a wholesale shift to graduate entry will address training post recruitment issues. 
The results indicated that more males were pursuing other employment opportunities than their female counterparts. Further exploration is needed to explain this phenomenon in more detail. The results indicated that for all other career behaviours there was no significant differences within the groups. The fact there are few differences between male and female doctors may be due to all doctors, irrespective of gender, starting to value similar characteristics within career posts or sharing similar worklife values. ${ }^{50-52}$ Given this, perhaps medicine needs to be promoting all training routes and flexible working for everyone regardless of gender or family status.

A real strength of this study was the high response rate that yielded an opportunity to survey a contemporary population of all F2 doctors in the UK. Additionally, we focused on the link between career intentions at the outset of the FP, and immediate career-related intentions at the end of the second year of the FP (F2), something that has not been done previously. However, our study did have limitations. The survey data are self-reported, and we could not cross-reference survey responses with training post applications and offers. The latter data are held in ORIEL, ${ }^{53}$ a centralised online system for managing specialty recruitment and career progression in medical training. At the time of this study to have compared responses on the career destination survey with ORIEL data would have required independently linking the two datasets, which are held by different bodies. In the future, this will be possible via UK Medical Education Database (UKMED)..$^{54}$

The destinations survey is not a research tool but a routine, administrative survey used for quality management and workforce planning purposes. Thus, our study was dependent on the equivalent of 'routine' clinical data, data which are not collected for research purposes. This posed some difficulties related to question formatting. Some questions asked for career intentions at the beginning of the programme, which participants may not have recalled accurately. The wording of some questions was ambiguous. Some questions used extensive response options or open comment boxes and thus did not lend themselves to statistical analysis. Key sociodemographic data such as country of origin or home country were not collected, so we had no means of assessing how many of the respondents who choose not to apply for specialty training in the UK were not UK citizens. We have given feedback to those managing this survey, and some questions have been amended accordingly. This bodes well for future research using this tool.

This relative consistency between career intention and career behaviour at the early stages of a medical career has been seen elsewhere in the literature. ${ }^{6910}$ However, previous studies have not framed their research questions theoretically, limiting generalisability. We drew on the ТPB as the basis for proposing that intention to engage in a career behaviour would be a predictor that this specific behaviour is likely to occur. ${ }^{141819}$ Our findings give preliminary evidence to support the utility of using the TPB to look in more detail at the specific factors (in terms of attitudes and beliefs, subjective norms and behavioural control) which drive junior doctor career behaviour. For example, it would be useful to consider how environmental factors, such as experiences during the FP as highlighted in the GMC's recent report, ${ }^{43}$ moderate behavioural intention in those who change their career direction between starting and completing the FP. The perceived norm component of the TPB may also provide a framework for considering how behaviour has changed, from almost all foundation doctors going directly into specialty (residency) training, to fewer than half doing so. Understanding medical career behaviour in this way may help inform the design of interventions to increase the attractiveness to Foundation doctors of applying for specialty training at the end of the FP. ${ }^{55}$

This study has other implications for future research, policy and practice. As discussed above, further research is needed to explore why career intentions change throughout the F2 programme-and what workplace and personal factors, such as wishing to work in the same region as a partner, might be influential. In terms of practice, it may be useful to routinely collect data on training intentions from the point of applications to medical school, as has been done in other contexts in relation to rural working intention. ${ }^{56}$ This would enable longitudinal follow-up to assess the relative contribution of medical school, FP and other major educational experiences on career intention.

We found that graduate entrants to medical school were more likely to immediately pursue higher training opportunities than those who entered medicine as school leavers. At a superficial level, this might suggest that shifting to graduate entry medicine may be a means of ensuring training posts are filled and junior doctors do not take time out of training. However, we would not advocate graduate entry medicine as a panacea as research discussed previously shows that graduates have their own problems in progressing through specialty training ${ }^{29}$ and dealing with stress. ${ }^{49}$ Instead, we propose that careers counselling in medical schools should be targeting 'non-graduate' entrant medical students to ensure they are equipped with the appropriate skills and knowledge to allow them to make informed careers decisions by the end of medical school/during the FP. For example, it may be that medical schools could focus more on providing career advice and delivering this in some way, so students are encouraged to reflect on how certain specialities are similar, or different, and to consider what they want in a job (eg, patient continuity, teamworking).

In terms of policy, medical student numbers are highly regulated by the UK governments. This workforce planning needs to take into account that more than half of those finishing the FP do not go directly into specialty training. This does not mean, however, that they are lost to the workforce. We suggest extending the number of opportunities for doctors at this stage of their career, 
and skills and competences gained in this time formally recognised.

In conclusion, medical education is a huge investment for countries and individuals, so it is crucial to understand factors which might predict doctors' future career behaviours. ${ }^{55}$ This study has identified that initial F1 intention is a good indicator of career behaviour at the end of F2. We propose that the discourse in the UK needs to change from concern that F2 doctors wish to take time out of training post-FP, to one of acceptance that things must change, and systems need to adapt. ${ }^{56-58}$ Most doctors are seeking out other employment or skill development opportunities within the UK after F2 and there may be ways by which these opportunities could be developed further, to help junior doctors develop transferable skills and knowledge which are acknowledged by training systems.

Acknowledgements Our thanks to all those FP2 doctors who participated in the survey. Our thanks also to the Foundation Programme Directors across the UK for allowing permission to conduct research on this data set. No patients or any members of the public were involved in this study.

Collaborators This project was carried out in collaboration with the UK Foundation Programme and NHS Education for Scotland (NES).

Contributors This project was part of a larger doctoral thesis project for GMS's doctorate, for which JC, PJ and KW obtained the funding. GMS prepared the ethics application. GMS led on the literature review. The data management and analysis were carried out by GMS, with consultation from SAS. GMS drafted the paper, with $\mathrm{JC}$ revising drafts. All authors reviewed the final draft and approved the paper. The study is guaranteed by the University of Aberdeen.

Funding Our thanks go to NHS Education for Scotland for funding Gillian Scanlan's programme of work through the Scottish Medical Education Research Consortium (SMERC).

Competing interests KW was the special advisor (Recruitment) for the UK's Foundation Programme (UKFPO).

Patient consent for publication Not required.

Provenance and peer review Not commissioned; externally peer reviewed.

Data sharing statement The data reported is from the UKFPO dataset, and any data shared would need the permission of the UK Foundation Programme directors.

Open access This is an open access article distributed in accordance with the Creative Commons Attribution Non Commercial (CC BY-NC 4.0) license, which permits others to distribute, remix, adapt, build upon this work non-commercially, and license their derivative works on different terms, provided the original work is properly cited, appropriate credit is given, any changes made indicated, and the use is non-commercial. See: http://creativecommons.org/licenses/by-nc/4.0/.

\section{REFERENCES}

1. Surman G, Goldacre MJ, Lambert TW. UK-trained junior doctors' intentions to work in UK medicine: questionnaire surveys, three years after graduation. J R Soc Med 2017;110:493-500.

2. Workload, recruitment, retention and moral. A BMA member briefing for the 3 May 2016 Special Representative Meeting. https://www. google.co.uk/search?q=BMA+2018+Evidence+Workforce+briefing \& $\mathrm{oq}=\mathrm{BMA}+2018+$ Evidence+Workforce+briefing\&aqs=chrome.69i57. 38176j1j7\&sourceid=chrome\&ie=UTF-8 (Accessed 8 Apr 2018).

3. UKFPO Career Destination Report 2016. www. foundationprogramme.nhs.uk/ download. asp? file= Careers destination_2016 Pdf (accessed 8 Mar 2017).

4. UK Foundation Programme Career Destinations Report 2017. http:// www.foundationprogramme.nhs.uk/download.asp?file=Career Destinations_Report_2017.pdf (Accessed 15 May 2018).

5. Scott I, Gowans M, Wright B, et al. Determinants of choosing a career in family medicine. CMAJ 2011;183:E1-E8.
6. Playford D, Ng W, Burkitt T. Redistributing the medical workforce: creation of a mobile rural workforce following undergraduate longitudinal rural immersion. Med Teach 2016;38:498-503.

7. Larkins S, Michielsen K, Iputo J, et al. Impact of selection strategies on representation of underserved populations and intention to practise: international findings. Med Educ 2015;49:60-72.

8. Odom Walker K, Ryan G, Ramey R, et al. Recruiting and retaining primary care physicians in urban underserved communities: the importance of having a mission to serve. Am J Public Health 2010;100:2168-75.

9. Rabinowitz HK, Diamond JJ, Veloski JJ, et al. The impact of multiple predictors on generalist physicians' care of underserved populations. Am J Public Health 2000;9:1225-8.

10. Herd MS, Bulsara MK, Jones MP, et al. Preferred practice location at medical school commencement strongly determines graduates' rural preferences and work locations. Aust $J$ Rural Health 2017;25:15-21.

11. Hann M, Reeves D, Sibbald B. Relationships between job satisfaction, intentions to leave family practice and actually leaving among family physicians in England. Eur J Public Health 2011;21:499-503.

12. Williams ES, Konrad TR, Scheckler WE, et al. Understanding physicians' intentions to withdraw from practice: the role of job satisfaction, job stress, mental and physical health. Health Care Manage Rev 2001;26:7-19.

13. Fishbein M, Ajzen I. Belief, attitude, intention and behaviour: An introduction to theory and research. Reading, MA: Addison. Wesley, 1975.

14. Ajzen I. The theory of planned behavior. Organ Behav Hum Decis Process 1991;50:179-211.

15. Ajzen I. The theory of planned behavior. In: van Lange PAM, Kruglanski AW, Higgins ET, eds. Handbook of theories of social psychology. London: Sage, 2012.

16. Weerasinghe CAK, Kumar S. Intention to pursue overseas jobs among university students and graduates: a case study from University of Peradeniya, Sri Lanka. Tropical Agricultural Research 2014;26:94-108.

17. Tegova S. Application of the theory of planned behaviour to career choice: The role of an improved measure of emotion. Edith Cowan University Research Online 2010. http://ro.ecu.edu.au/cgi/ viewcontent.cgi?article=2423\&context=theses_hons (Accessed 14 Aug 2018).

18. Arnold J, Loan-Clarke J, Coombs C, et al. How well can the theory of planned behavior account for occupational intentions? Journal of Vocational Behavior 2006;69:374-90.

19. Amani J, Mkumbo KA. Predictors of Career Intentions among Undergraduate Students in Tanzania. Journal of Education and Human Development 2016;5(No. 3):106-15.

20. Olanrewaju AK. Demographics, entrepreneurial self-efficacy and locus of control as determinants of adolescents' entrepreneurial intention in Ogun state, Nigeria. European Journal of Business and Social Science 2013;1:59-67.

21. Tolma EL, Reininger BM, Evans A, et al. Examining the theory of planned behavior and the construct of self-efficacy to predict mammography intention. Health Educ Behav 2006;33:233-51.

22. Gibis B, Heinz A, Jacob R, et al. The career expectations of medical students: findings of a nationwide survey in Germany. Dtsch Arztebl Int 2012;109:327-32

23. Ibrahim M, Fanshawe A, Patel V, et al. What factors influence British medical students' career intentions? Med Teach 2014;36:1064-72.

24. Dale J, Russell R, Scott E, et al. Factors influencing career intentions on completion of general practice vocational training in England: a cross-sectional study. BMJ Open 2017;7:e017143.

25. Miao Y, Li L, Bian Y, et al. Gender differences in job quality and job satisfaction among doctors in rural western China. BMC Health Serv Res 2017;17:848.

26. Pianosi K, Bethune C, Hurley KF. Medical student career choice: a qualitative study of fourth-year medical students at Memorial University, Newfoundland. CMAJ Open 2016;4:E147-E152.

27. Querido SJ, Vergouw D, Wigersma L, et al. Dynamics of career choice among students in undergraduate medical courses. A BEME systematic review: BEME Guide No. 33. Med Teach 2016;38:18-29.

28. Walsh J. Gender, the Work-Life Interface and Wellbeing: A Study of Hospital Doctors. Gender, Work \& Organization 2013;20:439-53.

29. Pyne Y, Ben-Shlomo Y. Older doctors and progression through specialty training in the UK: a cohort analysis of General Medical Council data. BMJ Open 2015;5:e005658.

30. Riska E. Gender and medical careers. Maturitas 2011;68:264-7.

31. Calvert MJ, Ross NM, Freemantle N, et al. Examination performance of graduate entry medical students compared with mainstream students. J R Soc Med 2009;102:425-30. 
32. Maiorova T, Stevens F, Scherpbier A, et al. The impact of clerkships on students' specialty preferences: what do undergraduates learn for their profession? Med Educ 2008;42:554-62.

33. Goldacre MJ, Laxton L, Lambert TW. Medical graduates' early career choices of specialty and their eventual specialty destinations: UK prospective cohort studies. BMJ 2010;341:c3199.

34. van der Horst K, Siegrist M, Orlow P, et al. Residents' reasons for specialty choice: influence of gender, time, patient and career. Med Educ 2010;44:595-602.

35. Kumwenda B, Cleland JA, Prescott GJ, et al. Relationship between sociodemographic factors and selection into UK postgraduate medical training programmes: a national cohort study. BMJ Open 2018:8:e021329.

36. Kumwenda B, Cleland J, Greatrix R, et al. Are efforts to attract graduate applicants to UK medical schools effective in increasing the participation of under-represented socioeconomic groups? A national cohort study. BMJ Open 2018;8:e018946.

37. Scanlan GM, Cleland J, Johnston P, et al. What factors are critical to attracting NHS foundation doctors into specialty or core training? A discrete choice experiment. BMJ Open 2018;8:e019911.

38. Playford D, Ngo H, Gupta S, et al. Opting for rural practice: the influence of medical student origin, intention and immersion experience. Med J Aust 2017;207:154-8.

39. Scanlan GM, Cleland J, Walker K, et al. Does perceived organisational support influence career intentions? The qualitative stories shared by UK early career doctors. BMJ Open 2018;8:e022833.

40. Rough Guide to the Foundation Programme, 2015, 2015. http://netfs. dev.itcs.co.uk/news/rough-guide-to-the-foundation-programme. (Accessed 16 May 2016).

41. Lachish S, Goldacre MJ, Lambert T. Associations between perceived institutional support, job enjoyment, and intentions to work in the United Kingdom: national questionnaire survey of first year doctors. BMC Med Educ 2016:16:151.

42. Spooner S, Pearson E, Gibson J, et al. How do workplaces, working practices and colleagues affect UK doctors' career decisions? A qualitative study of junior doctors' career decision making in the UK. BMJ Open 2017;7:e018462.

43. GMC Report General Medical Council. National training surveys 2018: initial findings report. 2018 www.gmc-uk.org/-/media/ documents/dc11391-nts-2018-initial-findings-report_pdf-75268532. pdf (Accessed 1 Aug 2018)

44. Lunenburg FC. Self-efficacy in the workplace: implications for motivation and performance. Inter $\mathrm{J}$ of Management, Business, and Administration 2011:14-1.
45. Bandura A. Social foundations of thought and action: A social cognitive theory. Englewood Cliffs, NJ: Prentice Hall, 1986.

46. Creed P, Patton W. Causal relationship between career indecision and career decision-making self-efficacy a longitudinal cross-lagged analysis. Journal of Career Development 2006;33:47-65.

47. Creed P, Patton W, Watson M. Cross-cultural equivalence of the career decision-making self-efficacy scale-short form: an Australian and South African Comparison. Journal of Career Assessment 2002;10.

48. Grayson MS, Newton DA, Thompson LF. Payback time: the associations of debt and income with medical student career choice. Med Educ 2012;46:983-91.

49. Casey D, Thomas S, Hocking DR, et al. Graduate-entry medical students: older and wiser but not less distressed. Australas Psychiatry 2016;24:88-92.

50. Scanlan G, Skåtun D, Johnston P, et al. Today's doctors: how do male and female early career preferences and behaviour differ? In preparation.

51. Humphries N, Crowe S, Brugha R. Failing to retain a new generation of doctors: qualitative insights from a high-income country. BMC Health Serv Res 2018:18:144.

52. Alton L. How Millennials Are Reshaping What's Important In Corporate Culture. Forbes 2018. https://www.forbes.com/sites/ larryalton/2017/06/20/how-millennials-are-reshaping-whatsimportant-in-corporate-culture/\#7ecb8ff02dfb (Accessed 3 Aug 2018).

53. NHS Oriel. https://www.oriel.nhs.uk/Web/Account/LandingPage. (Accessed 25 Aug 2018).

54. Dowell J, Cleland J, Fitzpatrick S, et al. The UK medical education database (UKMED) what is it? Why and how might you use it? BMC Med Educ 2018;18:6.

55. Francis J, Eccles MP, Johnston M, et al. Constructing questionnaires based on the theory of planned behaviour: A manual for health services researchers. Newcastle upon Tyne, UK: Centre for Health Services Research, University of Newcastle upon Tyne, 2004.

56. Tomblin Murphy G, Birch S, MacKenzie A, et al. A synthesis of recent analyses of human resources for health requirements and labour market dynamics in high-income OECD countries. Hum Resour Health 2016;14:59.

57. BMJ. Samantha Anthony: Career breaks should be supported, not feared. 2018. https://blogs.bmj.com/bmj/2018/03/16/samanthaanthony-career-breaks-should-be-supported-not-feared

58. BMA. My experience of taking a career break. $2017 \mathrm{https}: / / \mathrm{www}$. bma.org.uk/connecting-doctors/bmaspace/b/weblog/posts/taking-abreak-one-of-the-best-decisions-i-39-ve-ever-made. 